\section{Survival analysis of composite Dahl restorations provided to manage localised anterior tooth wear (ten year follow-up)}

\author{
A. B. Gulamali, ${ }^{1}$ K. W. Hemmings, ${ }^{2}$ C. J. Tredwin ${ }^{3}$ and A. Petrie ${ }^{4}$
}

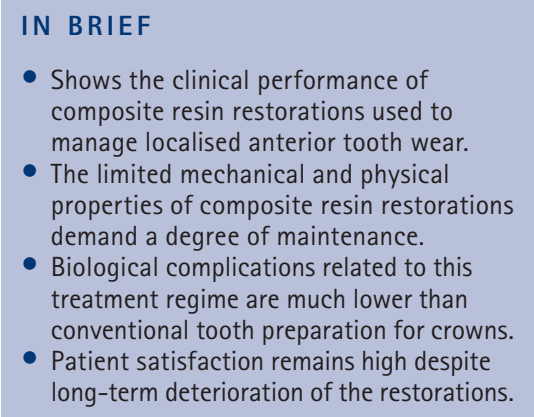

Objective To evaluate ten-year survival and clinical performance of resin-based composite restorations placed at increased vertical dimension as a 'Dahl' type appliance to manage localised anterior tooth wear. Design A prospective survival analysis of restorations provided at a single centre. Setting UK NHS hospital and postgraduate institute. Methods The clinical performance of 283 composite resin restorations on 26 patients with localised anterior tooth wear was reviewed after a ten year follow-up period. The study used modified United States Public Health Service (USPHS) criteria for assessing the restorations. Survival of the restorations was analysed using Kaplan-Meier survival curves, the log-rank test, and the Cox proportional hazards regression analysis. Results The results indicated that the median survival time for composite resin restorations was 5.8 years and 4.75 years for replacement restorations when all types of failure were considered. The restorations commonly failed as a result of wear, fracture and marginal discoloration. The factors that significantly influenced the survival of these restorations were the incisal relationship, aetiology, material used, and the nature of opposing dentition. The biological complications associated with this treatment regime were rare. Patient satisfaction remained high despite the long term deterioration of the restorations. Conclusion With some degree of maintenance, repeated use of composite resin restorations to treat localised anterior tooth wear at an increased occlusal vertical dimension is a viable treatment option over a ten-year period.

\section{INTRODUCTION}

There seems to be emerging evidence in recent years that pathological tooth wear is an increasing problem, particularly in young adults. The Children's Dental Health Survey UK (2003) ${ }^{1}$ noted increased prevalence of localised anterior tooth wear affecting 33\% of 15-year-olds. This showed a six percentage point increase in the proportion of affected young adults compared to the previous decade. This increase in prevalence is true for individuals of all socioeconomic backgrounds.

The aetiology and clinical appearance of tooth wear is frequently documented with

\footnotetext{
1*Specialist Registrar - Fixed and Removable Prosthodontics, ${ }^{2}$ Consultant in Restorative Dentistry, ${ }^{4} \mathrm{Head}$ of Biostatistics Unit and Senior Lecturer, UCL Eastman Dental Institute, 256 Gray's Inn Road, London, WC1X 8LD: ${ }^{3}$ Professor of Restorative Dentistry \&t Director of Clinical Dentistry, Peninsula College of Medicine and Dentistry, The John Bull Building, Tamar Science Park, Research Way, Plymouth, PL6 8BU

${ }^{*}$ Correspondence to: Akil B. Gulamali

Email: akilgulamali@aol.com; Tel: +44 (0)207 9152309
}

Online article number E9

Refereed Paper - accepted 4 March 2011

DOI: 10.1038/sj.bdj.2011.683

${ }^{\circ}$ British Dental Journal 2011; 211: E9 the terms 'erosion', 'abrasion', 'attrition' and more recently 'abfraction. However, in reality, the multifactorial nature of tooth wear means that these conditions usually occur in combination. ${ }^{2,3}$ In a large number of patients, the rate of tooth wear is slow. As tooth wear progresses with the reduction in the clinical crown height, the occlusal vertical dimension is frequently maintained by compensatory effects that attempt to maintain functional occlusal contacts. Dento-alveolar compensation occurs through continued tooth eruption, alveolar bone growth and apical cementum deposition, thus reducing the interocclusal space available for restoration. ${ }^{4}$ This phenomenon is common in patients with localised anterior tooth wear and restoration of these teeth becomes a challenge.

One of the options for creating interocclusal space is through relative axial tooth movement. In 1975, Dahl et al..$^{5}$ described the use of a removable cobalt-chromium partial bite-raising appliance to create interocclusal space in a patient with localised maxillary anterior tooth wear. It proved to be effective by a combination of orthodontic intrusion of teeth contacting the appliance and continued eruption of those held out of contact. ${ }^{6}$ The authors reported a 100\% success rate in achieving the desired interocclusal space in the subsequent 20 cases treated. The technique offered the obvious advantage in reducing the need to remove tooth tissue in order to accommodate any planned restorations. Several studies in the literature since have reported success in achieving the desired relative axial tooth movement using the Dahl principle, ranging from 93\% to $100 \%$ of all cases. ${ }^{7-11}$

The science and technology of composite dental restorative materials have advanced considerably over the years. Although composites have not evolved to the point of being an ideal restorative material, they have become a viable option to manage localised anterior tooth wear. The successful use of composite resin restorations placed at an increased occlusal vertical dimension as 'Dahl' type appliances has been demonstrated over the short-term. ${ }^{7-12}$ This simple technique offers better patient compliance compared 


\section{Table 1 Clinical assessment criteria used to assess the restorations}

\begin{tabular}{|c|c|}
\hline Anatomic form & $\begin{array}{l}\text { 1. The restoration is of a desirable form. } \\
\text { 2. The restoration is not of desirable form due to bulk fracture and requires } \\
\text { monitoring, refinishing, or repair. } \\
\text { 3. Sufficient material has been lost due to fracture or debonding that } \\
\text { replacement is necessary. }\end{array}$ \\
\hline Marginal adaptation & $\begin{array}{l}\text { 1. The restoration appears to adapt closely to the tooth along the periphery of the } \\
\text { restoration. An explorer does not catch when drawn across the margins, or if it } \\
\text { does catch it will only catch in one direction. } \\
\text { 2. The explorer catches and there is visible evidence of a crevice into which } \\
\text { explorer will penetrate. } \\
\text { 3. The explorer penetrates into a crevice that is of such depth that replacement } \\
\text { is necessary. }\end{array}$ \\
\hline Wear & $\begin{array}{l}\text { 1. There is no visible evidence of wear. } \\
\text { 2. There is visible faceting indicative of wear. } \\
\text { 3. There is gross wear resulting in exposure of tooth substance. }\end{array}$ \\
\hline Surface roughness & $\begin{array}{l}\text { 1. Surface of the restoration is smooth. } \\
\text { 2. Surface of the restoration is slightly rough or pitted; can be monitored, } \\
\text { refinished, or repaired. } \\
\text { 3. Surface of the restoration is deeply pitted or has irregular grooves or defects } \\
\text { not related to anatomy; cannot be refinished. }\end{array}$ \\
\hline $\begin{array}{l}\text { Marginal } \\
\text { discolouration }\end{array}$ & $\begin{array}{l}\text { 1. No visual evidence of marginal discolouration. } \\
\text { 2. Marginal discolouration of a superficial nature which can be monitored or } \\
\text { removed with minimal refinishing. } \\
\text { 3. More severe marginal discolouration which cannot be removed with further } \\
\text { refinishing and necessitates replacement. }\end{array}$ \\
\hline Colour match & $\begin{array}{l}\text { 1. The restoration matches in colour and blends well with the adjacent tooth structure. } \\
\text { 2. The mismatch in colour is within an acceptable range. } \\
\text { 3. The mismatch in colour is outside the acceptable range. }\end{array}$ \\
\hline Gingival health & $\begin{array}{l}\text { 1. There is no clinical evidence of gingival inflammation adjacent to the restoration. } \\
\text { 2. There is some evidence of mild gingival erythema adjacent to the restoration } \\
\text { but no bleeding on probing. } \\
\text { 3. There are obvious signs of gingival inflammation adjacent to the restoration but } \\
\text { no bleeding on probing. }\end{array}$ \\
\hline Postoperative pain & $\begin{array}{l}\text { 1. None. } \\
\text { 2. Mild; not requiring intervention of any nature. } \\
\text { 3. Moderate to severe requiring operative re-treatment or other clinical intervention. }\end{array}$ \\
\hline Posterior occlusion & $\begin{array}{l}\text { 1. Multiple, firm Shimstock holds between all pairs of posterior teeth. } \\
\text { 2. Some Shimstock holds between most but not all pairs of posterior teeth. } \\
\text { 3. No contact between any of the posterior teeth. }\end{array}$ \\
\hline
\end{tabular}

to the traditional removable Dahl appliance, ease of maintenance, conservation of tooth tissue and immediate improvement in aesthetics. The minimally invasive and conservative nature of the treatment regime offers an obvious advantage when restoring the already compromised worn anterior teeth. The aim of this study was therefore to evaluate the long term (ten years) survival and clinical performance of resin-based composite 'Dahl' type restorations provided at an increased occlusal vertical dimension (OVD) used to manage localised anterior tooth wear.

\section{METHOD}

\section{Sample}

The study was granted with a favourable ethical opinion by the NHS National Research Ethics Service, Charing Cross Research Ethics Committee. The sample involved a group of 26 patients, 18 males and 8 females, treated for localised anterior tooth wear with composite resin 'Dahl' restorations placed at an increased occlusal vertical dimension. The oldest patient was 80 years old and the youngest was 28 years old. These patients were treated between April 1994 and April 1999 at the Eastman Dental Hospital. All patients included in the study had the initial treatment provided at least ten years before the point of recall for this study. In the past, these patients were reviewed every six months for the first two years following the initial treatment, followed by a five-year review. Informed consent was obtained from all the patients enrolled in the study.

A total of 283 restorations were reviewed in the 26 patients after a ten year followup period. This included restorations that were initially placed and any subsequent replacement over the ten-year period. All the restorations that were replaced were considered as new restorations. The restorations that were subsequently replaced with crowns were classified as failed restorations. The composite resin restorations provided at the initial treatment were placed as either direct restorations, indirect restorations, or a combination of these. For teeth that were restored with a combination of direct and indirect restorations, the restorations were considered as single restorations.

A total of 186 teeth were restored, 78.5\% being in the maxilla and $21.5 \%$ in the mandible. Out of all the 283 restorations reviewed, 77 were on the canines, 87 on lateral incisors and 119 on central incisors.

Around 75\% of the restorations were placed by consultants and the remaining $25 \%$ were placed by senior clinical staff and postgraduate students.

\section{Collection of data}

The collection of data involved a full history and clinical examination; reference to clinical records; assessment of restorations using modified United States Public Health Services (USPHS) criteria; radiographic analysis; and statistical analysis following database creation of the clinical findings.

\section{Clinical records}

Access to past dental records enabled confirmation of all details pertinent to the aetiology and the initial placement of the restorations. Similarly, the clinical records of all restorations that were repaired or replaced could be noted on the data collection pro-forma. The clinical records, including some previous intra-oral photographs and study casts, served to rectify any discrepancies that became evident during data collection.

\section{Recall examination}

At recall, a history and clinical examination was carried out where data were collected. This involved recording of the following information:

- Patient details (name, hospital number, date of birth, gender)

- Treatment details (treatment date, operator, and aetiology of tooth wear)

- Restoration details (material used, opposing dentition, and occlusal relationship)

- Restoration assessment (USPHS criteria scores) 


\begin{tabular}{|l|l|}
\hline \multicolumn{2}{|c|}{ Table 2 Distribution of tooth wear aetiology } \\
\hline Suspected aetiology & Number of patients \\
\hline Primarily erosion & 12 \\
\hline Primarily abrasion & 2 \\
\hline Primarily attrition & 1 \\
\hline Combined factors & 11 \\
\hline Total & 26 \\
\hline
\end{tabular}

- Restoration failure details (history and date of repair or replacement, tooth involved, and cause of failure)

- Patient satisfaction (based on existing restorations and willingness to have the same treatment again).

Intra-oral digital clinical photographs and study casts were obtained and compared to the patient's previous clinical photographs and study casts.

Radiographic examination was undertaken where clinically indicated and in the best interest of the patient. All patients had a radiographic assessment as part of their initial treatment management. These radiographs were part of their clinical records and allowed comparison and analysis with any radiographs taken at recall.

\section{Restoration assessment}

Restorations were clinically assessed by direct evaluation using the modified United States Public Health Service (USPHS) criteria $^{13-15}$ and allocated a score of 1, 2 or 3 as shown in Table 1. Calibration of a single assessor revealed an unweighted inter-examiner kappa score of 0.779, indicating substantial agreement, and an intra-examiner score of 0.886 , indicative of almost perfect agreement. ${ }^{16}$

\section{Patient satisfaction}

Patient satisfaction was assessed at two levels: the aesthetic satisfaction of the surviving restorations, and the overall experience of the initial treatment.

Patients were asked to comment on the aesthetics of the surviving restorations as a whole. The response was graded according to the following:

1. Patient has no complaints and is pleased with the aesthetics

2. Patient has some reservations but accepts the aesthetics

Table 3 Restorative material distribution among sample

\begin{tabular}{l|l|l} 
Material & Number of patients & Number of restorations \\
\hline Direct composite resin & 15 & 190 \\
\hline Indirect composite resin & 8 & 63 \\
\hline Combined direct/indirect & 3 & 30 \\
\hline Total & 26 & 283 \\
\hline
\end{tabular}

Table 4 Nature of opposing dentition

\begin{tabular}{l|l|l}
\hline Material & Number of restorations & Percentage of restorations \\
\hline Natural teeth & 154 & 54.4 \\
\hline Composite resin & 124 & 43.8 \\
\hline Porcelain & 5 & 1.8 \\
\hline Total & 283 & 100
\end{tabular}

Table 5 Number of restorations placed in different incisal relations

\begin{tabular}{l|l|l}
\hline Incisor relation & Number of patients & Number of restorations \\
\hline Class I & 7 & 97 \\
\hline Class II Division 1 & 3 & 17 \\
\hline Class II Division 2 & 8 & 84 \\
\hline Class III & 8 & 85 \\
\hline Total & 26 & 283
\end{tabular}

3. Patient is unhappy about the aesthetics and requests intervention.

Finally, the response to the willingness of having the initial treatment again, if appropriate, was graded as follows:

1. Yes; very happy with the initial treatment

2. Maybe; not sure if would like the treatment again

3. No; unhappy with the initial treatment.

\section{Survival analysis}

The data collated was entered on a spreadsheet run by the software Statistical Programme for Social Sciences (SPSS.14) and STATA Version 10. The objective of the analysis was to assess the survival function of the restorations and to ascertain what clinical factors may exert a significant effect on the survival of restorations placed using this treatment regime. The variables included in the analysis were:

1. Patient gender

\section{Operator}

3. Aetiology of tooth wear (Table 2)

4. Material (Table 3)

5. Nature of opposing dentition (Table 4) 6. Incisal relationship (Table 5).

The baseline date was taken as the date of restoration placement. Survival of a restoration was defined as the interval between the date of placement and the date of failure. A restoration that was replaced was re-entered as a new restoration. Those restorations that did not fail at the end of the period of study were considered to be surviving and included in the statistical analysis.

Survival analysis was carried out at two different levels of failure:

1. Major failure: defined as any restorations that required complete replacement and included any recall restoration that had a USPHS score of 3

2. Combined major and minor failure: included all restorations in the major 
failure group, all those that had required repair or refinishing for any reason, and those that were placed in the USPHS score of 2 for any of the assessment criteria. Exception to this was when restorations were surviving and the only USPHS score of 2 was related to wear, the rest of the assessment criteria scoring a USPHS score of 1 . As wear of the restorations was an almost universal finding, there remained a risk of giving an inaccurate impression of overall performance. This methodology was consistent with the previous study by Redman et al. ${ }^{11}$

Survival analysis was performed on each variable initially using the KaplanMeier approach to assess the effect of that variable on survival. Log rank tests were performed addressing the null hypothesis that there are no differences in the overall survival times in the categories of the variable of interest. If the log rank test gave $p<0.05$, it was concluded that the categories of that variable differed significantly in their effect on the survival of the restorations. Where $p<0.05$ and the variable had more than two categories, each pair of categories was compared by the log rank test to establish where the differences lay and to assist in calculating baseline hazards for the subsequent Cox proportional hazards model. This Cox proportional hazards regression analysis was used to evaluate the independent effects of the different variables included in the model on the survival of the restorations.

\section{RESULTS}

\section{Re-establishment of posterior occlusion}

All the patients were reviewed earlier by Redman et al. ${ }^{11}$ who noted re-establishment of posterior tooth contact in all the patients, ranging from just under 2 months to 18 months, with a mean of 7 months.

of the 26 patients reviewed for this study, 21 patients $(81 \%)$ carried on to exhibit complete re-establishment of posterior occlusion with Shimstock foil holding firmly between all pairs of posterior teeth. The remaining five patients (19\%) exhibited occlusal contacts between most but not all the pairs of posterior teeth. Invariably,

\begin{tabular}{|c|c|c|c|c|c|c|}
\hline \multirow{2}{*}{$\begin{array}{l}\text { Cause of failure } \\
\text { Fracture }\end{array}$} & \multicolumn{2}{|c|}{$\begin{array}{l}\text { Minor failure } \\
\text { (number and \% of } \\
\text { all } 283 \text { restorations) }\end{array}$} & \multicolumn{2}{|c|}{$\begin{array}{l}\text { Major failure } \\
\text { (number and \% of } \\
\text { all } 283 \text { restorations) }\end{array}$} & \multicolumn{2}{|c|}{$\begin{array}{l}\text { Combined failure } \\
\text { (number and } \% \text { of } \\
\text { all } 283 \text { restorations) }\end{array}$} \\
\hline & 35 & $12.4 \%$ & 26 & $9.2 \%$ & 61 & $21.6 \%$ \\
\hline Decementation & 2 & $0.7 \%$ & 29 & $10.2 \%$ & 31 & $10.9 \%$ \\
\hline Replaced by cast restoration & - & - & 23 & $8.1 \%$ & 23 & $8.1 \%$ \\
\hline Caries & - & - & 3 & $1.1 \%$ & 3 & $1.1 \%$ \\
\hline Anatomic form & 7 & $2.5 \%$ & 22 & $7.8 \%$ & 29 & $10.3 \%$ \\
\hline Marginal adaptation & 31 & $10.9 \%$ & 9 & $3.2 \%$ & 40 & $14.1 \%$ \\
\hline Wear & 70 & $24.7 \%$ & 59 & $20.8 \%$ & 129 & $45.5 \%$ \\
\hline Surface roughness & 28 & $9.9 \%$ & 8 & $2.8 \%$ & 36 & $12.7 \%$ \\
\hline Marginal discolouration & 69 & $24.3 \%$ & 13 & $4.6 \%$ & 82 & $28.9 \%$ \\
\hline Colour match & 30 & $10.6 \%$ & 5 & $1.8 \%$ & 35 & $12.4 \%$ \\
\hline Postoperative pain & 1 & $0.35 \%$ & 5 & $1.8 \%$ & 6 & $2.15 \%$ \\
\hline Gingival health & 9 & $3.2 \%$ & - & - & 9 & $3.2 \%$ \\
\hline
\end{tabular}

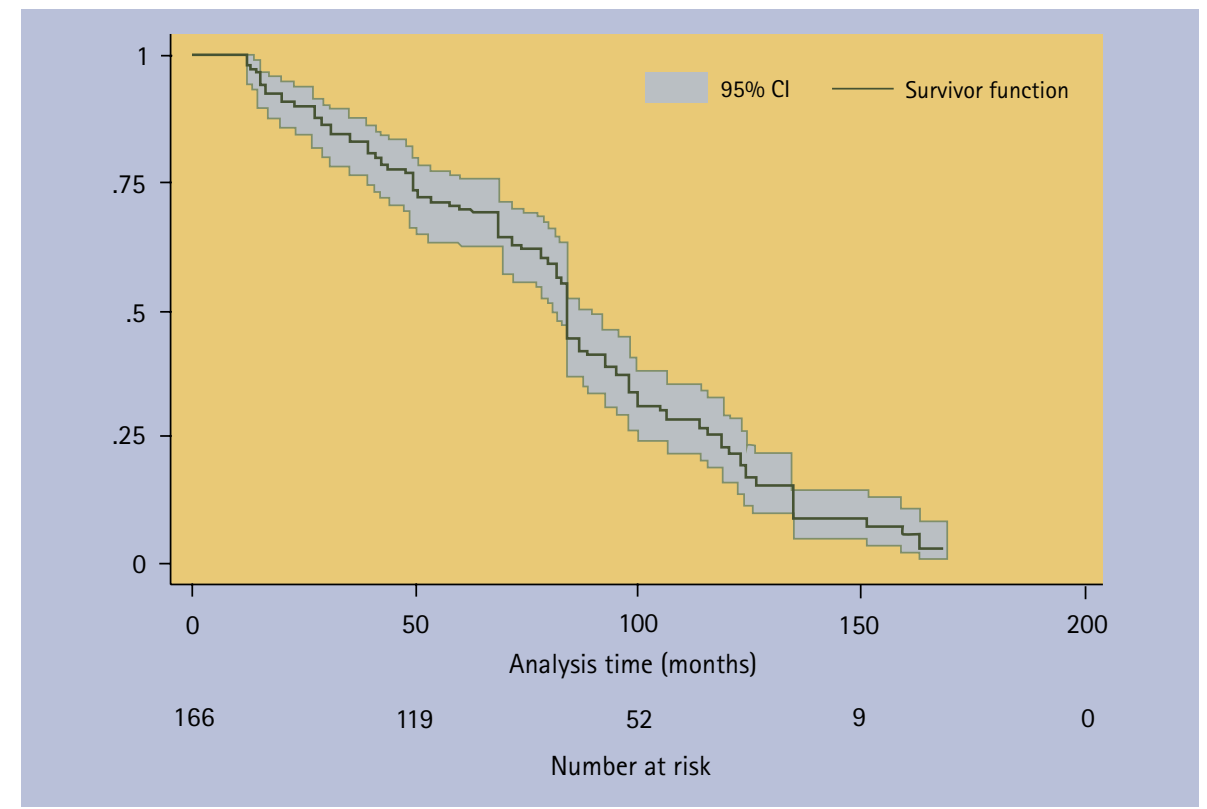

Fig. 1 Kaplan-Meier survival plot for major failures in all restorations ( $95 \%$ confidence interval)

this lack of occlusal contact occurred in the first molar and premolar region.

\section{Failure of restorations}

More than $50 \%$ of the restorations had major failures. These included the ones that had been subsequently replaced by new restorations and any restorations that were surviving but had failed and required replacements. Around 7\% of the restorations surviving were successful and exhibited no failure modes.

The majority of the minor failures that had an intervention involving repair in the past were due to minor fracture of the restorations, most notably along the incisal edges. Other reasons included staining and marginal discolouration, and recementation of indirect restorations.

When considering all the failures, combining major and minor failures, the majority of the restorations failed as a result of wear (45.5\%), marginal discolouration (28.9\%) and fracture (21.6\%) (Table 6).

\section{Survival analysis}

The median survival time (MST) for all the restorations was 7.0 years when considering major failure modes only (Fig. 1). This means that considering the group as 


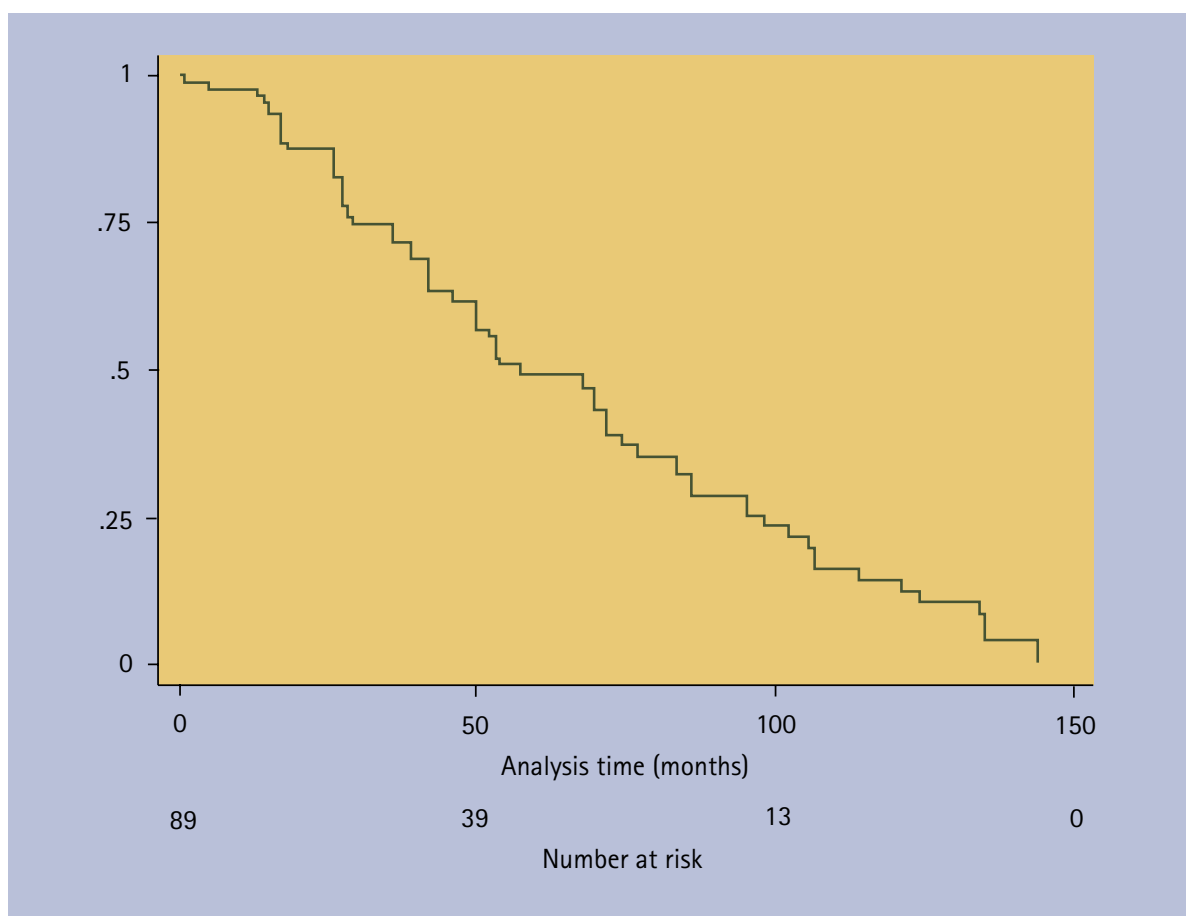

Fig. 2 Kaplan-Meier survival plot for major failures in restorations that were replaced

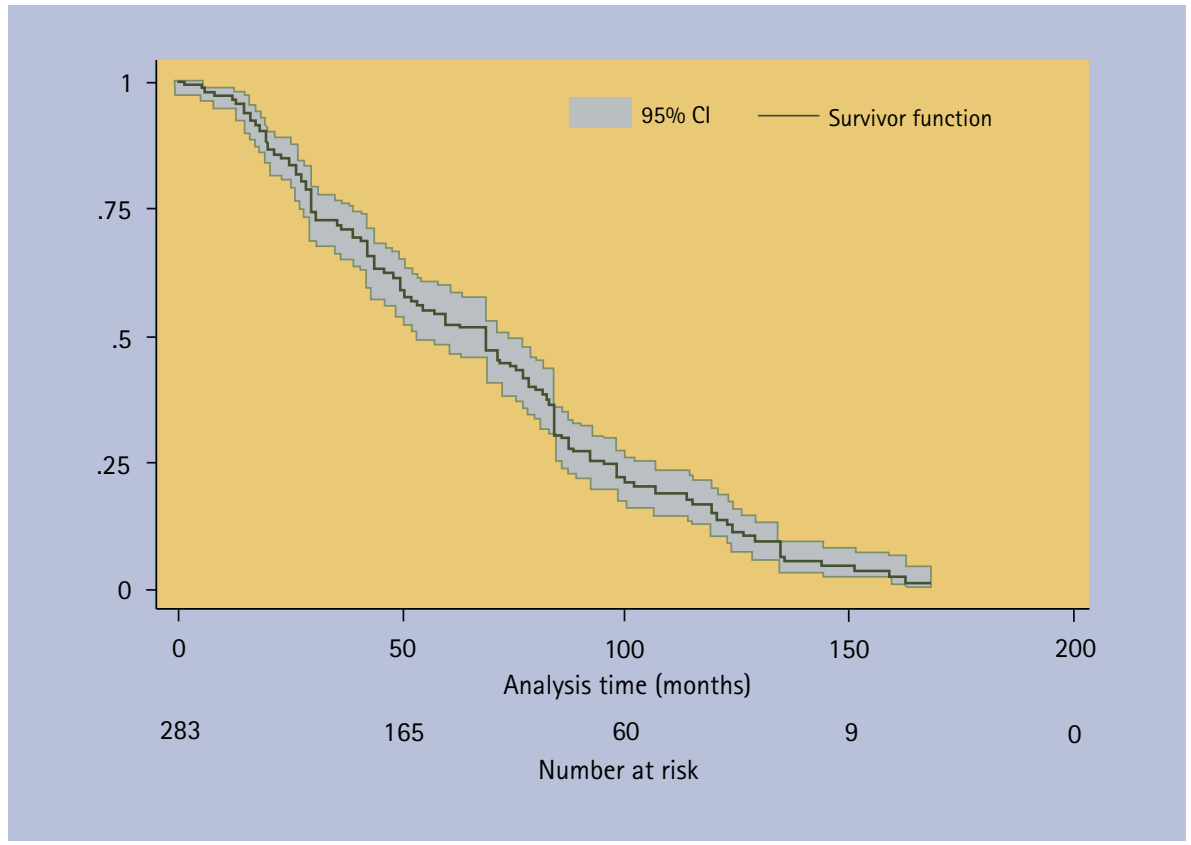

Fig. 3 Kaplan-Meier survival plot for combined major and minor failures in all restorations (95\% confidence interval)

\begin{tabular}{l|l|l}
\hline \multicolumn{2}{|l}{ Table 7 Significant clinical variables affecting survival outcome $(p<0.05)$} \\
\hline Clinical variable & $\begin{array}{l}\text { Major failure } \\
p\end{array}$ & $\begin{array}{l}\text { Major and minor failure } \\
p\end{array}$ \\
\hline Gender & 0.068 & 0.098 \\
\hline Aetiology & 0.001 & 0.005 \\
\hline Operator & 0.928 & 0.101 \\
\hline Material & 0.239 & 0.017 \\
\hline Opposing dentition & 0.001 & 0.009 \\
\hline Incisor relations & 0.0006 & 0.0006 \\
\hline
\end{tabular}

a whole, there was a 50\% probability that a composite restoration placed using this treatment regime would survive 7.0 years. However, when considering the survival of restorations placed as replacements, the MST for these restorations was 4 years and 9 months (Fig. 2). At combined major and minor failure levels the MST was 5 years and 9 months (Fig. 3).

Further statistical analysis involving log rank tests and Cox proportional hazards model revealed incisal relation, aetiology, and nature of opposing dentition as significant variables affecting survival rates when considering major failures (Table 7). The incisal relation Class I, the aetiological factor of abrasion, and the opposing porcelain surface significantly reduced the survival rates of the composite restorations. However, at combined major and minor failure level, only the aetiological factor of abrasion and indirect placement of composite material were significantly associated with reduced survival.

\section{Biological complications}

Of the 26 patients, one patient had received root fillings on two of the teeth three years after the initial restorations were placed as a result of irreversible pulpitis. Another patient had three restorations replaced due to secondary caries. Although these complications may be related to the composite treatment provided, the precise causes remain uncertain as this was not objectively analysed during the period of the study, and the findings were purely incidental at the point of recall.

Biological complications that were unlikely to be due to the composite treatment included a patient who had a single root filling that was completed before the initiation of the treatment due to previous trauma. Another case presented with generalised adult chronic periodontal disease, with the anterior teeth exhibiting radiographic signs of moderate bone loss and clinical mobility of grade II. A third patient had two restorations replaced by post crowns, both presenting with apical radiolucency and clinical signs of chronic apical periodontitis. Apart from these findings, no other pathology was observed.

\section{Patient satisfaction}

In four of the patients reviewed, a total of 23 restored teeth were subsequently 
replaced by cast restorations. Of the remaining 22 patients, eight had no complaints and were still pleased with the results (Figs 4-7). Around ten patients had some reservations (Figs 8 and 9), and only four were unhappy and requested intervention (Figs 10 and 11). All these patients were very satisfied with the initial treatment they had received and expressed willingness to have the same treatment again when necessary.

\section{DISCUSSION}

This study shows that the use of composite resin restorations has proved to be a viable medium-term option to treat localised anterior tooth wear at an increased OVD. The desired tooth movements occur in a manner and timescale similar to that of other Dahl appliances. However, more than $90 \%$ of the restorations exhibited minor or major failure over the preceding ten years and required intervention and maintenance. The restorations commonly failed due to wear, marginal discolouration and fracture, frequently occurring in combination. The failure modes expose the limited mechanical and physical properties of composite resin used in this way.

The MST of 5 years and 9 months is comparable to the previous study by Redman et al. ${ }^{11}$ who noted a MST of 4 years and 9 months over a six-year period when all types of failure were considered. Interestingly, the restorations placed as replacements exhibited a reduced survival rate when considering major failures. The replacement of restorations in these compromised teeth will often involve bonding to dentine. The limitations of bonding composite resin to dentine despite the use of dentine bonding agents are well documented. ${ }^{17,18}$

At both levels of failure, major and combined major and minor, patients with abrasion as the primary aetiological factor had restorations with significantly poorer survival outcome when compared to erosion, attrition, or combined aetiology. However, only two patients had abrasion diagnosed as a primary aetiological factor and had a habit of chewing pencils. These two patients constituted a small proportion of the sample and the results need to be interpreted with caution. Both the patients were continuing their habits when reviewed.

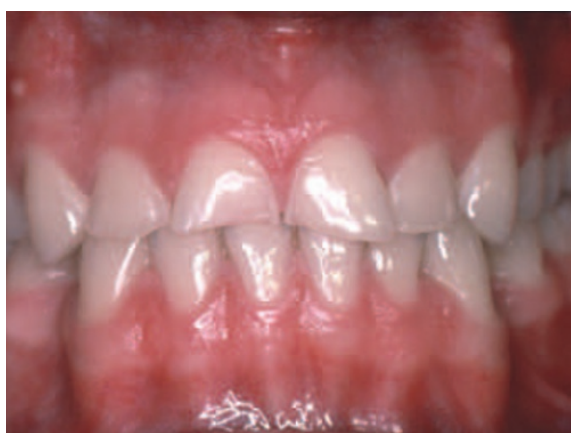

Fig. 4 PATIENT A. Anterior view of teeth at initial presentation in May 1994

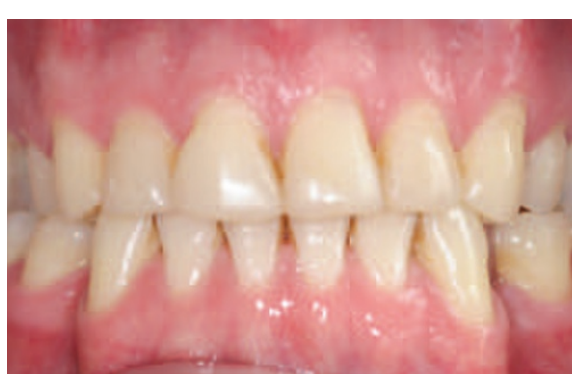

Fig. 6 PATIENT A. Restorations in

October 2008, patient expressed high satisfaction

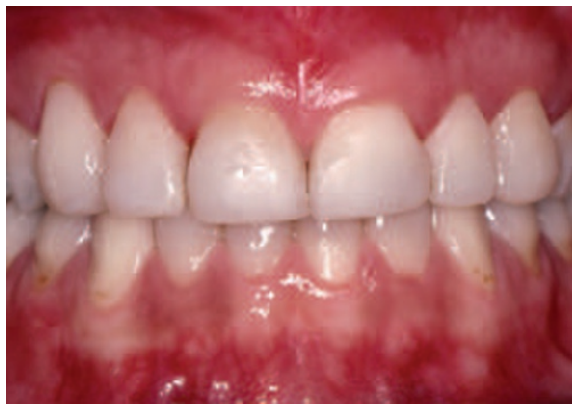

Fig. 8 PATIENT B. Postoperative view of restorations in November 1994

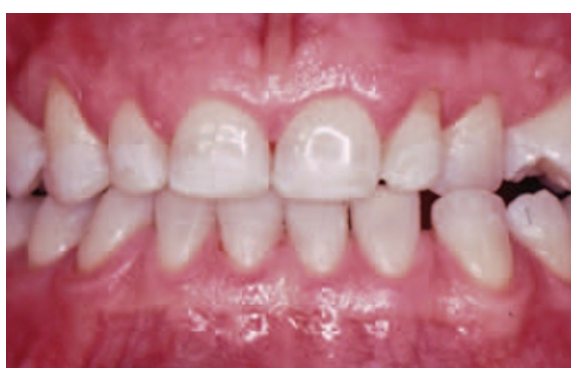

Fig. 10 PATIENT C. Restorations after placement in August 1997

The statistical analysis suggest that for major failures requiring replacement of the restorations, there was no significant difference between direct, indirect, or for the technique utilising the combination of the materials. These findings are similar to those found by Wassell et al. ${ }^{19,20}$ and Van Dijken ${ }^{21}$ where no significant differences in longevity were noted between directly

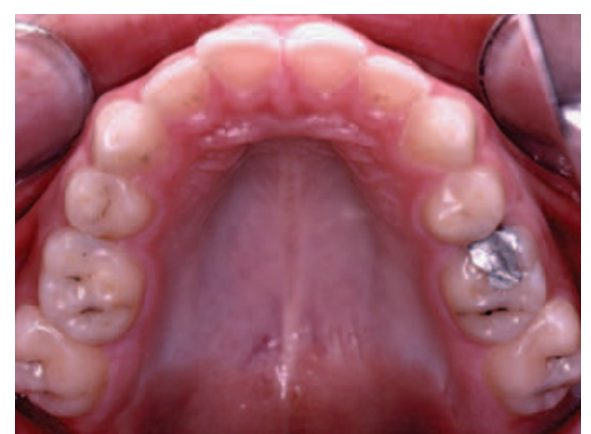

Fig. 5 PATIENT A. Occlusal view of anterior teeth at initial presentation in May 1994

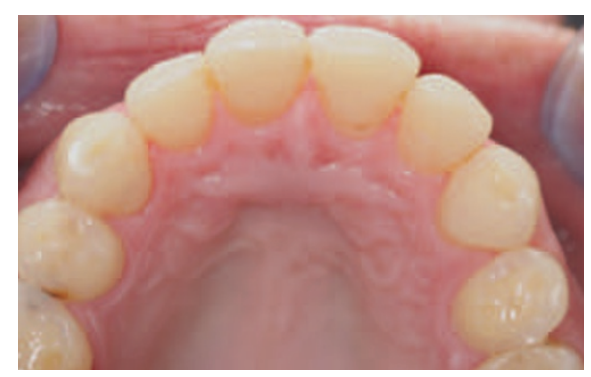

Fig. 7 PATIENT A. Occlusal view of the restorations in October 2008, then in service and successful

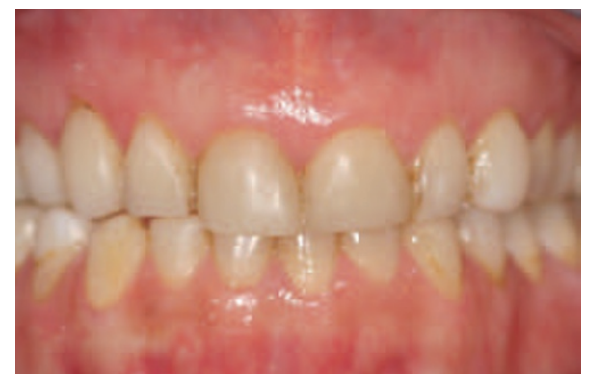

Fig. 9 PATIENT B. Restorations in September 2008. Patient expressed some reservations with regards to marginal staining

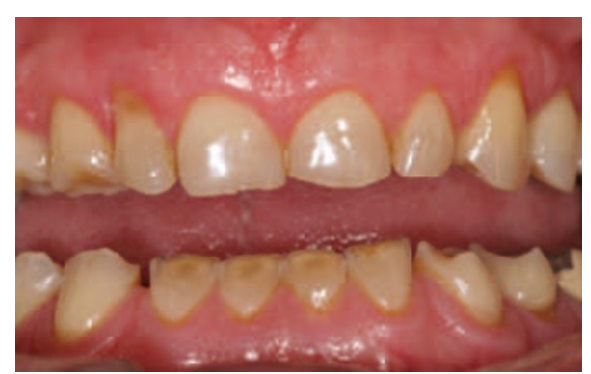

Fig. 11 PATIENT C. Major failure of restorations as noted in March 2008. Patient expressed dissatisfaction and requested intervention

and indirectly fabricated composite Class II restorations. There seems to be a significantly greater degree of minor failures with indirect restorations compared to direct or combined restorations. However, frequency analysis of the common failure modes of wear, fracture and marginal discolouration did not reveal significant predilection for 
indirect composites. The results may be explained by the fact that fewer indirect composites were placed compared to direct composites. As severity of wear and the number of teeth affected increased, the decision to treat with indirect restorations was more likely. The disproportionate sample in this category again may explain why failure events for indirect composites appear to be significant.

The different structure and physical properties of tooth substance and dental restorative material in dynamic occlusion eventually results in their differential wear. There is no current restorative material that is able to satisfy the requirements of an ideal restorative material from this respect. The results suggest that at a major failure level, composite restorations performed significantly worse when opposed by porcelain. There was no significant difference in the longevity of the restorations when opposed by similar composite resin materials or natural teeth. However, only five restorations were opposed by porcelain which may bias this finding. Nevertheless, several studies have shown the marked abrasive nature of porcelain compared to other restorative materials such as gold alloy and composite resin. ${ }^{22,23}$ In contrast to porcelain, Willems et $a l .{ }^{24}$ have demonstrated modern composite resin restorations to have similar wear rates to human enamel, supporting its use in the management of tooth wear.

The nature of the incisal relationships has been suggested to affect the survival outcome of composite resin restorations placed using this treatment regime. Redman et al. ${ }^{11}$ noted the Class II Division 2 group to have significantly reduced survival outcome at both major and combined failures levels. The possibly unfavourable and higher shear and tensile forces placed on the restorative material associated with Class II Division 2 and Class III occlusions may result in higher failure rates. However, the analysis of results from this study suggest otherwise. At the major failures level, there was a statistically significant difference between Class III and both Class I and Class II Division 2. The restorations in Class III groups had significantly better survival outcome than Class I or Class II Division 2 groups. The samples within these groups were uniformly proportionate. It was therefore surprising to see that patients with a Class I occlusion appeared to have a relatively poor performance with composite restorations used in this study. The amount of parafunction may be more important than the incisal relationship but this was not measured. Some patients may have initially presented with a pseudo-Class III occlusion and restored to a Class I. The progressive wear of the restorations may then resume a pseudo-Class III occlusion again. The incisal relationship was not a significant factor when considering all failures, both major and minor.

The biological complications associated with this treatment regime were very low. Only $2 \%$ of all the restorations that had major failures were replaced as a result of secondary caries. Only one patient had two teeth develop symptoms of irreversible pulpitis three years after the initial placement of the restorations. In reality, it is impossible to assess accurately the pulpal condition of the tooth which has been compromised by tooth wear. The condition will depend on the cumulative effects of pathological and iatrogenic insults imposed on the tooth with time. ${ }^{25}$ It may therefore be possible that the pulp, or some part of the pulp, already showed signs of irreversible pulpitis but these were not manifested clinically at the time of initial placements. This compares favourably to conventional crowns where endodontic complications develop in 19\% of the restored teeth. ${ }^{26}$

The patient satisfaction remained high despite long-term failures and maintenance involved. Only four patients were unhappy about the aesthetic results at this stage of recall. These patients presented with restorations that had major failures, and invariably required intervention. All the patients when questioned stated that they were happy with the initial treatment. Comments were made about the simplicity of the procedure, tolerance of the procedure, immediate improvement in symptoms and aesthetics, and ease of maintenance. The technique takes time but is conservative of tooth structure and avoids or delays the need for conventional preparation.

It was interesting to find that five of out of the 26 patients reviewed presented with only partial stability of posterior occlusion after a ten year follow-up period. None of these patients were aware of their partial stability or reported any concerns. Further studies may consider the factors that can be used to predict the eruptive potential of the dentition and the long-term consequences of a partially established posterior occlusion.

\section{CONCLUSION}

Repeated use of composite resin restorations placed at an increased occlusal vertical dimension as a 'Dahl' type appliance to manage localised anterior tooth wear is a viable treatment option in the short- to medium-term. The restorations are susceptible to failures and require a degree of maintenance. However, the biological complications associated with this treatment regime are rare and patient satisfaction remains high.

1. Lader D, Chadwick B, Chestnutt I et al. Children's dental health in the United Kingdom, 2003. London: Office of National Statistics, 2005. http://www. statistics.gov.uk/STATBASE/Product.asp?vlnk=12918

2. Eccles J D. Tooth surface loss from attrition, erosion and abrasion. Dent Update 1982; 9: 373-381.

3. Smith B G N, Knight J K. A comparison of patterns of tooth wear with aetiological factors. Br Dent J 1984; 157: 16-19.

4. Setchell D J. Tooth surface loss: part 12. Conventional crown and bridge work. Br Dent $J$ 1999; 187: 68-74.

5. Dahl B L, Krogstad O, Karlsen K. An alternative treatment in cases with advanced localised attrition. J Oral Rehabil 1975; 2: 209-214.

6. Dahl B L, Krogstad O. The effect of a partial bite raising splint on the occlusal face height. An x-ray cephalometric study in human adults. Acta Odontol Scand 1982; 40: 17-24.

7. Poyser N J, Porter R W, Briggs P F, Chana H S, Kelleher M G, Patel M M. The evaluation of direct composite restorations for the worn mandibular anterior dentition - clinical performance and patient satisfaction. J Oral Rehabil 2007; 34: 361-376.

8. Gough M B, Setchell D J. A retrospective study of 50 treatments using an appliance to produce localised occlusal space by relative axial tooth movement. Br Dent J 1999; 187: 134-139.

9. Gow $A M$, Hemmings $K$ W. The treatment of localised anterior tooth wear with indirect Artglass. Results after two years. Eur J Prosthodont Restor Dent 2002; 10: 101-105.

10. Hemmings K W, Darbar U R, Vaughan S. Tooth wear treated with direct composite restorations at an increased vertical dimension. Results at 30 months. J Prosthet Dent 2000; 83: 287-293.

11. Redman C D J, Hemmings K W, Good J A. The survival and clinical performance of resin based composite restorations used to treat localised anterior tooth wear. Br Dent J 2003; 194: 566-572

12. Darbar $U$ R, Hemmings $K W$. Treatment of localised anterior tooth wear with composite restorations at an increased occlusal vertical dimension. Dent Update 1997: 24: 72-75.

13. Cvar J F, Ryge G. United States Public Health Service publication number 720-244. San Francisco: US Government Printing Office, 1970.

14. Ryge G, Snyder M. Evaluating the clinical quality of restorations. J Am Dent Assoc 1973; 87: 369-377.

15. Ryge G. Clinical criteria. Int Dent J 1980; 30: 347-358.

16. Landis J R, Koch G G. The measurement of observer agreement for categorical data. Biometrics 1977; 33: $159-174$.

17. Soderholm K J. Does resin based dentine bonding work? Int Dent J 1995; 45: 371-381. 
18. Perdigao J. New developments in dental adhesion. Dent Clin North Am 2007; 51: 333-357.

19. Wassall R W, Walls A W G, McCabe J F. Direct composite inlays versus conventional composite restorations: three-year clinical results. Br Dent J 1995; 179: 343-349.

20. Wassall R W, Walls A W G, McCabe J F. Direct composite inlays versus conventional composite restorations: five-year follow up. J Dent 2000; 28: $375-382$.
21. Van Dijken J W V. Direct resin composite inlays/ onlays: an 11 year follow-up. J Dent 2000; 28: 299-306.

22. Mahalick J A, Knap F J, Weiter E J. Occlusal wear in prosthodontics. J Am Dent Assoc 1971; 82: 154-159.

23. Hudson J D, Goldstein G R, Georgescu M. Enamel wear caused by three different restorative materials. J Prosthet Dent 1995; 74: 647-654.

24. Willems $G$, Lambrechts $M$, Braem M, Vanherle G.
Three-year follow-up of five posterior composites: in vivo wear. J Dent 1993; 21 : 74-78.

25. Langeland $K$, Langeland B K. Pulp reaction to crown preparation, impression, temporary crown fixation and permanent cementation. J Prosthet Dent 1965; 15: $129-142$

26. Saunders W P, Saunders E M. Prevalence of periradicular periodontitis associated with crowned teeth in an adult Scottish population. Br Dent $J$ 1998; 185: 137-140. 